\title{
A study on influence of lifestyle and breakfast skipping on body image concern among post graduate students
}

\author{
LIPSA DASH, MONIKA SATPATHY AND VIJAYETA PRIYADARSHINI
}

Received: 10.02.2017; Revised: 08.04.2017; Accepted: 25.04.2017

See end of the paper for authors' affiliations LIPSA DASH

Department of Home Science, Sambalpur University, BURLA (ODISHA) INDIA

Email : dashlipsa28@gmail.com; lipsadash@suniv.ac.in
ABSTRACT : Adolescence is a transitional period and college life is an important stage as at this time like behaviours are conducive to change. Dietary intake during adolescence contributes to lifelong eating habits and the development of early risk factors for disease in adulthood. Insight into breakfast consumption of adolescents is of public health concern, for several reasons as it has been associated with positive outcomes for diet quality, BMI status and lifestyle factors. Studies suggest that eating a breakfast which contains sufficiently balanced nutrients has a beneficial impact on both student health - in terms of nutrient intake height-toweight ratio and early physical development- and cognitive skills such as focused attention and memory recall. In the research study the researcher had studied aiming on the objectives like - to access association of body image in skipping breakfast, lifestyle of post graduate students, impact of skipping breakfast on memory and concentration, taking 46 (Female) post graduate students as sample size of Sambalpur University. According to the results of the current study it was found that 60.87 per cent agreed whereas 39.13 per cent denied, that students breakfast skipping shows an impact on memory and 82.6 per cent agreed whereas 17.4 per cent denied that they felt difficulty in doing their work and concentrate if they do not consume breakfast. As per BMI 54.35 per cent were under weight, 36.96 per cent were normal weight and 8.69 per cent were obese, respectively. A significant variation in life style and body image was observed.

KEY WORDS: Lifestyle, Breakfast skipping, Body image, Concentration, Post graduate students.

- HOW TO CITE THIS PAPER : Dash, Lipsa, Satpathy, Monika and Priyadarshini, Vijayeta (2017). A study on influence of lifestyle and breakfast skipping on body image concern among post graduate students. Asian J. Home Sci., 12 (1) : 131-134, DOI: 10.15740/HAS/AJHS/12.1/131-134. 